\title{
Biomechanical evaluation of single- and multi-level anterior cervical discectomy and fusion with polyetheretherketone cages: radiological and clinical outcomes
}

\author{
Gabriela Zapolska ${ }^{1}$, Michał Kwiatkowski ${ }^{2}$ Grzegorz Turek ${ }^{3}$, Zenon Mariak ${ }^{4}$, Adam Hermanowicz ${ }^{5}$ \\ ${ }^{1}$ Department of Paediatric Radiology, Medical University of Bialystok, Bialystok, Poland \\ ${ }^{2}$ Department of Paediatric Orthopaedics, Medical University of Bialystok, Bialystok, Poland \\ ${ }^{3}$ Department of Neurosurgery, Brodno Masovian Hospital, Warsaw, Poland \\ ${ }^{4}$ Department of Neurosurgery, Medical University of Bialystok, Bialystok, Poland \\ ${ }^{5}$ Department of Paediatric Surgery and Urology, Medical University of Bialystok, Bialystok, Poland
}

\begin{abstract}
Objective. The aim of this study was to analyse the outcomes of single- and multi-level anterior cervical discectomy and fusion (ACDF) with standalone polyetheretherketone (PEEK) cages, with particular emphasis on the risk of secondary adjacent segment disease.

Materials and methods. This retrospective study included 30 patients with single- or multi-level cervical disc herniation. Before the ACDF, and one year thereafter, the patients underwent clinical and radiological evaluation including determination of cervical pain severity with a numerical rating scale (NRS), and a survey with a Polish adaptation of the neck disability index questionnaire (NDI-PL). Biomechanical parameters of the cervical spine were determined using the Cobb method.

Results. One year after ACDF, all patients had achieved complete fusions, and $97 \%$ showed a significant reduction of pain severity. Also, a significant decrease in all NDI-PL indices was observed. A significant decrease in overall cervical spine mobility coexisted with a significant increase in the mobility of the segment above the one operated upon and a non-significant decrease in the mobility of the segment below. No statistically significant change was found in the intervertebral disc space height (IVH) above and below the operated segment, and no evidence of degeneration within the segments adjacent to the operated one was documented.

Conclusion. One- and two-level ACDF with standalone PEEK cages provided high fusion rates. Surgical spondylosis contributed to a reduction of spinal mobility despite the hypermobility in adjacent spinal segments. No degeneration in adjacent spinal segments was documented within a year of ACDF, and the treatment seemed to improve patients' quality of life.
\end{abstract}

Key words: adjacent segment degeneration, adjacent segment disease, anterior cervical discectomy with fusion, cervical myelopathy, cervical radiculopathy, PEEK cages

(Neurol Neurochir Pol 2019; 53 (5): 358-362)

\section{Introduction}

Anterior cervical discectomy and fusion (ACDF) is a well-known form of surgical intervention in symptomatic cervical spondylosis. ACDF includes removal of the migrated disc (discectomy), decompression of neural structures within the spinal canal, and stabilisation of the interbody implant at the operated level. Adjacent segment disease (ASD) has become an important issue in patients with single- or multi-level cervical disc disease who undergo the ACDF procedure. ASD is defined as new degenerative changes in spinal segments adjacent to the previously operated one(s), associated with related symptoms [1].

Theoretically, the development of surgical techniques for interbody fusion with preservation of spinal mobility should contribute to a lower incidence of ASD. The ACDF-imposed alterations of spinal biomechanics may accelerate degenerative changes within adjacent segments of the cervical spine; 
however, the exact pathomechanism of this process is still not completely understood [2]. Patients after ACDF showed radiographic evidence of various degenerative changes within adjacent spinal segments, which may pose a substantial diagnostic and therapeutic challenge. Although ACDF results in the attenuation of clinical symptoms, it is also associated with decreased spinal mobility, greater mechanical overload, and accelerated degeneration of adjacent segments, which may produce new clinical symptoms such as radiculopathy, myelopathy, stenosis and instability [3,4].

In this paper, we present radiological and clinical outcomes of single- and multi-level ACDFs with polyetheretherketone (PEEK) implants, with particular emphasis on the risk of secondary ASD.

\section{Materials and methods}

The retrospective study included 30 consecutive patients with single- or multi-level cervical disc herniation who between January and December 2013 underwent ACDF using a standard Cloward procedure with standalone PEEK cages at the Department of Neurosurgery, Medical University of Bialystok, Poland. Three patients were excluded from the analysis because of a history of systemic diseases (rheumatoid arthritis - one patient, osteoporosis - two patients).

The protocol of the study was approved by the Local Bioethics Committee at the Medical University of Bialystok (decision no. R-I-002/40/2013).

The study patients presented with single- or multi-level cervical spine disease ( $\mathrm{C} 3$ to $\mathrm{C} 7$ ). Only those patients with cervical radiculopathy, myelopathy with neurological deficits or without, and spondylosis diagnosed based on MRI, were included in the analysis. Patients with physical deformities, infections, metabolic bone diseases or tumours were excluded.

Before the ACDF, and 12 months post-procedure, all participants of the study were subjected to a comprehensive clinical and radiological evaluation. The clinical evaluation consisted of history taking, physical and neurological examination, assessment of pain severity with a numerical rating scale (NRS) and a survey with a Polish adaptation of the neck disability index questionnaire (NDI-PL).

Spinal radiographs (anterior-posterior, lateral and flexion-extension) were obtained preoperatively and one year after the ACDF. Functional parameters of the cervical spine were determined based on Cobb angle measurement, a method used routinely to calculate the spinal curvature angles. Overall mobility of cervical spine and segmental mobility in the operated and adjacent segments determined prior to the ACDF were compared with respective parameters obtained 12 months post-procedure. The measurement methodology is set out in Figure 1.

Intervertebral disc space height (IVH) was measured for the operated segment and adjacent segments. Moreover, fusion (subsidence, antero-posterior implant displacement) and reconstruction of the intervertebral disc space height were evaluated. Fusion was defined as the lack of translucency around the PEEK cage, the presence of adhesion mass-fusion bone between the vertebral bodies, and the absence of motion between the spinous processes on flexion-extension radiographs. An interspinous distance $\geq 2 \mathrm{~mm}$ on functional radiographs was defined as non-fusion [5]. Cervical alignment was determined as the angle formed by the imaginary lines tangent to the posterior edges of $\mathrm{C} 2$ and $\mathrm{C} 7$. Subsidence was defined as the loss of height in the operated segment(s) on lateral radiographs, $>3 \mathrm{~mm}$ and $>5 \mathrm{~mm}$ for one- and two-level procedures, respectively [6, 7]. Intervertebral disc space height (IVH) was defined as the mean value of the anterior and posterior height of the disc, expressed in millimetres.

The follow-up radiographs were screened for ASD by two independent observers blinded to the clinical outcomes. ASD was defined by the presence of at least one of the following: calcification of the anterior longitudinal ligament; narrowing of the disc space with or without posterior osteophytes; and/ or formation of a new anterior osteocyte or enlargement of a preexisting osteophyte [8].

\section{Statistical analysis}

The results were analysed with a Statistica 10.0 package from StatSoft. Statistical characteristics of the study variables were presented as means, their standard deviations, medians, minimum and maximum values. NDI-PL scores were compared using the Wilcoxon test, and mobility of the spinal segments with the non-parametric Kruskal-Wallis test. The significance of intragroup differences in overall and segmental spinal mobility was verified with the Wilcoxon test and the significance of intergroup differences in the spinal mobility with the non-parametric Mann-Whitney U-test. The threshold of statistical significance for all tests was set at $\mathrm{p}<0.05$.

\section{Results}

The study included 16 men (53.3\%) and 14 women (46.7\%) with a mean age of 56 years (range 27-67 years). All data was collected retrospectively. Mean duration of follow-up was 12 months. Four patients achieved fusion at $\mathrm{C} 3 / \mathrm{C} 4$, another four at $\mathrm{C} 4 / \mathrm{C} 5,19$ at C5/C6, and 14 at C6/C7. No patients required additional surgery for recurrent symptoms.

Up to $97 \%$ of the patients who underwent ACDF reported a significant decrease in pain severity expressed on NRS. Furthermore, a statistically significant decrease in all NDI-PL indices (i.e. pain intensity, personal care, lifting, reading, headaches, concentration, work, driving, sleeping, and recreation) was documented, along with a significant improvement in daily functional activity. The first pre-op measurement amounted to c. $47 \%$ of disability, the last amounted to c. $15 \%$, defining minimal disability.

Fusion rates for $\mathrm{C} 2-\mathrm{C} 7$ at three and 12 months post-procedure were $95.7 \%$ and $100 \%$, respectively. No subsidence 

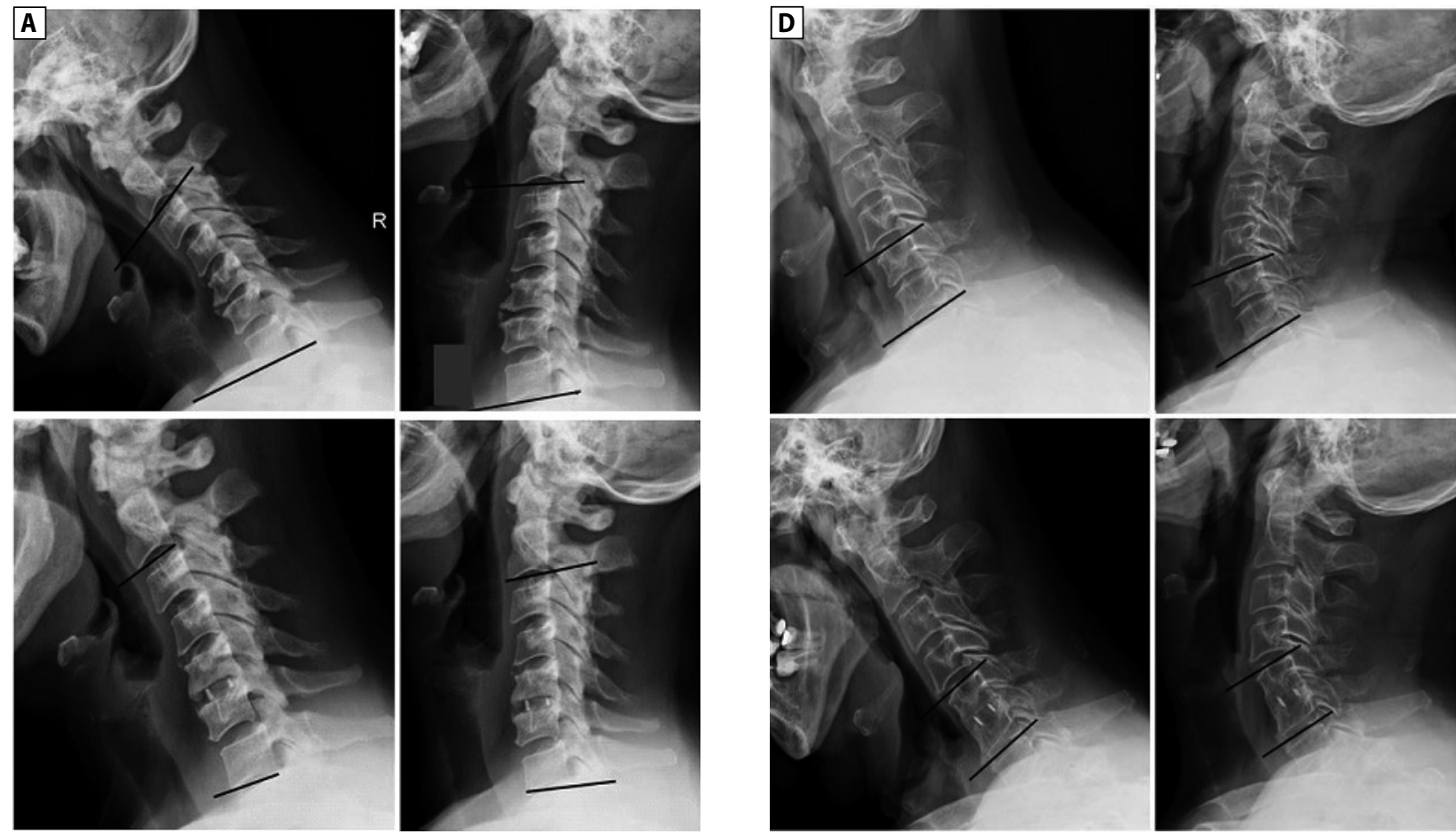

Figure 1. Measurement of spinal mobility: (A) ROM for C2-C7, (B) ROM for the segment located above the operated one, (C) ROM for the segment located below the operated one, (D) ROM for the operated segment. All ROM values determined based on Cobb angle measurement, on archival radiographs from the Department of Neurosurgery, Medical University of Bialystok

of vertebral bodies on the PEEK implant was observed at the operated level. At the end of the follow-up period, a statistically significant decrease in overall cervical spine mobility (C2-C7) was observed, along with a significant increase in the mobility of the segment located above the operated one, and a non-significant decrease in the mobility of the segment located below. No statistically significant change was found in the IVH above and below the operated segment. No evidence of degeneration within the segments adjacent to the operated one was documented during the follow-up period, and none of the patients required repeated ACDF for the adjacent segments 12 months after the primary procedure.

\section{Discussion}

Although ACDF is an effective method for the treatment of degenerative cervical disease, it can also result in overload and hypermobility of adjacent spinal segments [3]. Based on a systematic review of the literature, Sugawara [9] concluded that $2-36 \%$ of patients subjected to ACDF may develop symptomatic degenerative changes in adjacent spinal segments within 10 years of the procedure, which in 6-19\% of cases may require further surgical treatment. In two studies with a minimum three-year follow-up [10], the incidence of radiological adjacent segment pathologies (RASP), such as heterotrophic calcification of the anterior longitudinal ligament and narrowing of the disc space with or without posterior osteophytes, exceeded $30 \%$, and $10.5 \%$ of patients after cervical spine surgeries showed evidence of heterotrophic calcification. This can cause a secondary lack of flexibility within the previously operated segment of cervical spine. According to Mehren et al. and Heidecke et al., heterotrophic calcifications may be found in up to $29 \%$ of patients, whereas Tortolani et al. reported them as a rare and late complication of cervical surgeries [11-13].

In our present study, patients subjected to ACDF did not show any evidence of degenerative changes such as heterotrophic calcifications within one year of the procedure. The lack of symptomatic ASD in our series was probably associated with the fact that the patients were followed-up for a shorter period than the participants in previous, larger studies [14]. Our follow-up was short, limited to one year only. This represents a major limitation of our study. However, we continue to follow this cohort, and we hope that additional data will be available in the future.

The aetiology of ASD is complex, and no single cause or risk factor for this pathology have been identified thus far. ASD may be a consequence of a preexisting disease, physiological age-related degenerative process, hypermobility in adjacent spinal segments, changes in intradiscal pressure, anatomical anomalies or sagittal misalignment [15]. According to Lawrence et al. [16], the risk factors for ASD after cervical fusion surgery included age $<60$ years, fusion adjacent to $\mathrm{C} 5$ $\mathrm{C} 6$ and/or C6-C7, preexisting disc herniation, and/or dural compression secondary to spinal stenosis. In turn, Katsuura et 
al. [17] found a direct correlation between symptomatic ASD and the loss of lordotic curvature in the sagittal cervical spine. Published opinions vary about the contribution of surgical technique or operative management to the incidence of ASD. Song et al. [18] found no association between the incidence of clinical ASD and the number of fused segments. Hilibrand et al. [1] followed up 374 patients who underwent 409 cervical fusion procedures over a 20 -year period. Approximately $25 \%$ of the patients developed symptomatic ASD within 10 years of the procedure, with an annual incidence rate of $2.9 \%$. The incidence of ASD was shown to be higher after C5-C6 and C6-C7 fusions. According to some authors, the risk of ASD within an adjacent segment after a single-level fusion is higher in patients with CT-myelography or MRI evidence of preexisting degenerative changes [19].

Other key factors implicated in ASD are altered biomechanics and mobility of adjacent spinal segments, resulting from inappropriate cervical alignment. Biomechanical changes in adjacent segments after the fusion, such as altered range of motion or intradiscal pressure, have been reported by several authors $[10,18]$. However, in our present study, the hypermobility of the adjacent spinal segment above the operated one did not exert an effect on the incidence of ASD within one year of ACDF, and we did not find statistically significant changes in IVH above and below the operated segment.

Also, the effect of soft tissue disruption on the biomechanics of adjacent spinal segments should be considered as a factor predisposing to ASD. Some previous studies found an association between the ossification of adjacent spinal segments in patients implanted with anterior cervical plates who eventually developed ASD. Park et al. [20] measured the distance between the intervertebral disc and the metal plate implanted during ACDF with plate fixation and found no association between this parameter and the risk of secondary ASD. We cannot comment on this observation as no plate fixation was used in our patients.

In previous studies, ACDF provided good or excellent outcomes in $70-90 \%$ of patients with cervical radiculopathy, primarily due to the decompression of the neural structures [21]. Bohlman et al. [22] found a correlation between the lack of fusion and the incidence of postoperative neck pain. In our present study, the lack of subsidence and the presence of stable intervertebral spondylosis observed in all patients during the final control visit turned out to be associated with a significant attenuation of pain. No patients developed symptomatic pseudarthrosis that required a secondary surgery.

These findings imply that the implantation of PEEK cages is a safe procedure resulting in high fusion rates and good clinical and radiological outcomes.

Published evidence suggests that the appropriate alignment of sagittal cervical spine might be associated with better quality of life after ACDF. According to some authors, the reconstruction of IVH is of lesser importance. However, worse cervical alignment has been shown to correlate with poorer outcomes with regards to neck and arm pain, as well as with a higher likelihood of repeated surgical procedure. This implies that preservation of cervical lordosis is an important determinant of ACDF outcomes. Lordotic alignment contributes to better mobility and functioning of cervical spine. In turn, sagittal misalignment has been demonstrated to be associated with cervical instability, pain, and even unfavourable functional outcomes [23]. Attenuation of pain is without doubt a key determinant of the quality of life. Similarly to previous studies, our experiment demonstrated that ACDF contributed to a considerable improvement in the quality of life determined with NRS scores and the NDI-PL questionnaire. Thus, the outcomes of the treatment were not impeded by either a decrease in spinal mobility or a hypermobility of the spinal segment located above the operated one.

In this study, we analysed spinal biomechanics with a functional X-ray, using a routine, albeit highly reliable, Cobb method. Dvorak et al. [24] analysed functional radiographs from 64 patients with disorders of cervical spine. The patients were divided into three groups, i.e. cervical degeneration, radiculopathy, and cervical trauma, which were then compared to healthy controls so as to identify pathological patterns of motion. Tęsiorowski et al. [25] compared cervical mobility at three, six and 12 months post-surgery with normal cervical mobility of people aged 40-50. The analysis of functional radiographs demonstrated an evident local kyphotic deformity on lateral views.

\section{Conclusions}

One- and two-level ACDF with standalone PEEK cages provided high fusion rates. Spondylosis at one or two levels contributed to a reduction of spinal mobility despite the hypermobility in adjacent spinal segments. No degenerative changes in adjacent spinal segments were documented within a year of ACDF. Restoring IVH at the operated level seems to be less important from the perspective of functional outcome. ACDF improved the quality of life in patients with single- or multi-level cervical disc herniation.

Funding: No funding was received for this research.

Ethics: Compliance with ethical standards.

Conflict of interest: The authors declare no conflict of interest.

\section{References}

1. Hilibrand AS, Robbins M. Adjacent segment degeneration and adjacent segment disease: the consequences of spinal fusion? Spine J. 2004; 4(6 Suppl): 190S-194S, doi: 10.1016/j.spinee.2004.07.007, indexed in Pubmed: 15541666.

2. Litrico S, Lonjon N, Riouallon G, et al. French Society of Spine Surgery (SFCR). Adjacent segment disease after anterior cervical interbody fusion: a multicenter retrospective study of 288 patients with long-term follow-up. Orthop Traumatol Surg Res. 2014; 100(6 Suppl): S305-S309, doi: 10.1016/j.otsr.2014.07.004, indexed in Pubmed: 25129704. 
3. Carrier CS, Bono CM, Lebl DR. Evidence-based analysis of adjacent segment degeneration and disease after ACDF: a systematic review. Spine J. 2013; 13(10): 1370-1378, doi: 10.1016/j.spinee.2013.05.050, indexed in Pubmed: 23891293.

4. Matsumoto M, Okada E, Ichihara D, et al. Anterior cervical decompression and fusion accelerates adjacent segment degeneration: comparison with asymptomatic volunteers in a ten-year magnetic resonance imaging follow-up study. Spine (Phila Pa 1976). 2010; 35(1): 36-43, doi: 10.1097/BRS.0b013e3181b8a80d, indexed in Pubmed: 20023606.

5. Kaiser MG, Mummaneni PV, Matz PG, et al. Joint Section on Disorders of the Spine and Peripheral Nerves of the American Association of Neurological Surgeons and Congress of Neurological Surgeons. Radiographic assessment of cervical subaxial fusion. J Neurosurg Spine. 2009; 11(2): 221-227, doi: 10.3171/2009.3.SPINE08719, indexed in Pubmed: 19769501.

6. Gercek E, Arlet V, Delisle J, et al. Subsidence of stand-alone cervical cages in anterior interbody fusion: warning. Eur Spine J. 2003; 12(5): 513-516, doi: 10.1007/s00586-003-0539-6, indexed in Pubmed: 12827473.

7. Karikari IO, Jain D, Owens TR, et al. Impact of subsidence on clinical outcomes and radiographic fusion rates in anterior cervical discectomy and fusion: a systematic review. J Spinal Disord Tech. 2014; 27(1): 1-10, doi: 10.1097/BSD.0b013e31825bd26d, indexed in Pubmed: 24441059.

8. Li J, Li Y, Kong F, et al. Adjacent segment degeneration after single-level anterior cervical decompression and fusion: disc space distraction and its impact on clinical outcomes. J Clin Neurosci. 2015; 22(3): 566-569, doi: 10.1016/j.jocn.2014.08.019, indexed in Pubmed: 25487176.

9. Sugawara T. Anterior Cervical Spine Surgery for Degenerative Disease: A Review. Neurol Med Chir (Tokyo). 2015; 55(7): 540-546, doi: 10.2176/nmc.ra.2014-0403, indexed in Pubmed: 26119899.

10. Maldonado CV, Paz RDR, Martin CB. Adjacent-level degeneration after cervical disc arthroplasty versus fusion. Eur Spine J. 2011; 20 Suppl 3: 403407, doi: 10.1007/s00586-011-1916-1, indexed in Pubmed: 21796395.

11. Heidecke V, Burkert W, Brucke M, et al. Intervertebral disc replacement for cervical degenerative disease-clinical results and functional outcome at two years in patients implanted with the Bryan cervical disc prosthesis. Acta Neurochir (Wien). 2008; 150(5): 453-9; discussion 459, doi: 10.1007/s00701-008-1552-7, indexed in Pubmed: 18421412 .

12. Mehren C, Suchomel P, Grochulla F, et al. Heterotopic ossification in total cervical artificial disc replacement. Spine (Phila Pa 1976). 2006; 31(24): 2802-2806, doi: 10.1097/01.brs.0000245852.70594.d5, indexed in Pubmed: 17108833.

13. Tortolani PJ, Cunningham BW, Eng M, et al. Prevalence of heterotopic ossification following total disc replacement. A prospective, randomized study of two hundred and seventy-six patients. J Bone Joint Surg Am. 2007; 89(1): 82-88, doi: 10.2106/JBJS.F.00432, indexed in Pubmed: 17200314.
14. Bydon M, Xu R, De la Garza-Ramos R, et al. Adjacent segment disease after anterior cervical discectomy and fusion: Incidence and clinical outcomes of patients requiring anterior versus posterior repeat cervical fusion. Surg Neurol Int. 2014; 5(Suppl 3): S74-S78, doi: 10.4103/2152-7806.130676, indexed in Pubmed: 24843815.

15. Anakwenze OA, Auerbach JD, Milby AH, et al. Sagittal cervical alignment after cervical disc arthroplasty and anterior cervical discectomy and fusion: results of a prospective, randomized, controlled trial. Spine (Phila Pa 1976). 2009; 34(19): 2001-2007, doi: 10.1097/ BRS.0b013e3181b03fe6, indexed in Pubmed: 19730207.

16. Lawrence BD, Hilibrand AS, Brodt ED, et al. Predicting the risk of adjacent segment pathology in the cervical spine: a systematic review. Spine (Phila Pa 1976). 2012; 37(22 Suppl): S52-S64, doi: 10.1097/ BRS.0b013e31826d60fb, indexed in Pubmed: 22885828.

17. Katsuura A, Hukuda S, Saruhashi $Y$, et al. Kyphotic malalignment after anterior cervical fusion is one of the factors promoting the degenerative process in adjacent intervertebral levels. Eur Spine J. 2001; 10(4): 320-324, doi: 10.1007/s005860000243, indexed in Pubmed: 11563618.

18. Song KJ, Choi BW, Kim JK. Adjacent segment pathology following anterior decompression and fusion using cage and plate for the treatment of degenerative cervical spinal diseases. Asian Spine J. 2014; 8(6): 720-728, doi: 10.4184/asj.2014.8.6.720, indexed in Pubmed: 25558313.

19. Ishihara $\mathrm{H}$, Kanamori $\mathrm{M}$, Kawaguchi $\mathrm{Y}$, et al. Adjacent segment disease after anterior cervical interbody fusion. Spine J. 2004; 4(6): 624-628, doi: 10.1016/j.spinee.2004.04.011, indexed in Pubmed: 15541693.

20. Park JB, Watthanaaphisit T, Riew KD. Timing of development of adjacent-level ossification after anterior cervical arthrodesis with plates. Spine J. 2007; 7(6): 633-636, doi: 10.1016/j.spinee.2006.10.021, indexed in Pubmed: 17998121.

21. Rao RD, Currier BL, Albert TJ, et al. Degenerative cervical spondylosis: clinical syndromes, pathogenesis, and management. Instr Course Lect. 2008; 57: 447-469, indexed in Pubmed: 18399602.

22. Bohlman HH, Emery SE, Goodfellow DB, et al. Robinson anterior cervical discectomy and arthrodesis for cervical radiculopathy. Long-term follow-up of one hundred and twenty-two patients. J Bone Joint Surg Am. 1993; 75(9): 1298-1307, doi: 10.2106/00004623199309000-00005, indexed in Pubmed: 8408151.

23. Ferch RD, Shad A, Cadoux-Hudson TAD, et al. Anterior correction of cervical kyphotic deformity: effects on myelopathy, neck pain, and sagittal alignment. J Neurosurg. 2004; 100(1 Suppl Spine): 13-19, indexed in Pubmed: 14748568.

24. Dvorák J, Panjabi MM, Grob D, et al. Clinical validation of functional flexion/extension radiographs of the cervical spine. Spine (Phila Pa 1976). 1993; 18(1): 120-127, doi: 10.1097/00007632-19930100000018, indexed in Pubmed: 8434312.

25. Tęsiorowski M, Lipik E, Zarzycki D, et al. Wyniki leczenia jedno- i wielopoziomowej szyjnej choroby dyskowej z zastosowaniem sztucznego dysku szyjnego. J Orthop Trauma Surg Rel Res. ; 3(15): 55-61. 